ISSN 2089-8673

Jurnal Nasional Pendidikan Teknik Informatika (JANAPATI)

Volume 1, Nomor 3, Desember 2012

\title{
SISTEM INFORMASI GEOGRAFIS FASILITAS UMUM DAN SOSIAL DI KABUPATEN SERANG MENGGUNAKAN MAPSERVER DAN MYSQL SPASIAL
}

\author{
Mohammad lqbal $^{1}$, Gede Karya ${ }^{2}$ \\ 1,2) Jurusan Teknik Informatika, Fakultas Teknologi Informasi dan Sains \\ Universitas Katolik Parahyangan \\ Jl. Ciumbuleuit No. 94, Bandung 40141 \\ Email : 7307016@student.unpar.ac.id, gkarya@unpar.ac.id
}

\begin{abstract}
Abstrak
Kabupaten Serang merupakan salah satu kabupaten di Provinsi Banten. Dengan semakin meningkatnya jumlah penduduk tiap tahun menyebabkan kebutuhan fasilitas umum dan sosial meningkat pesat. Fasilitas umum dan sosial yang dimaksud seperti pendidikan, peribadatan, kesehatan, ekonomi/niaga, terminal, serta rekreasi dan olahraga. Dari data statistik 2010/2011 banyaknya dan jenis dari fasilitas umum dan sosial sangat kompleks, oleh karena itu perlu dilakukan pengelolaandan pemetaan fasilitas umum dan sosial lebih baik. Melalui pemetaan, pengambilan keputusan untuk mendirikan fasilitas umum dan sosial baru dapat dilakukan dengan mudah dan cepat.Untuk itu dikembangkan sebuah sistem informasi geografis (SIG) berbasis web menggunakan teknologi MapServer dan MySQL Spasial. Dengan SIG penyajian dan analisis informasi mengenai perkembangan fasilitas umum dan sosial lebih mudah dilakukan. Pengambilan keputusan dalam kerangka pendirian fasilitas umum dan sosial baru pun dapat dilakukan dengan lebih mudah, dengan mempertimbangkan aspek kewilayahan dan jarak terhadap fasilitas sejenis atau fasilias lain di sekitarnya.
\end{abstract}

Kata kunci : SIG berbasis web, mapserver, mysql spasial, php, fasilitas umum, fasilitas sosial.

\section{Pendahuluan}

\subsection{Latar Belakang Masalah}

Kabupaten Serang merupakan salah satu kabupaten di Provinsi Banten. Kabupaten ini berada di ujung barat laut Pulau Jawa, berbatasan dengan Kabupaten Tangerang di timur, Kabupaten Lebak di selatan, Kota Cilegon di barat, serta Laut Jawa dan Kota Serang di utara. Secara Geografis wilayah Serang terletak pada koordinat $50^{\circ} 50^{\prime}-60^{\circ} 21^{\prime}$ Lintang Selatan dan $105^{\circ} 0^{\prime}-106^{\circ} 22^{\prime}$ Bujur Timur. Luas wilayah Kabupaten Serang adalah 1.467,35 km², dengan total jumlah penduduk 1.571.174 jiwa dan kepadatan penduduk $1.070,73 \mathrm{jiwa} / \mathrm{km}^{2}$.

Dengan semakin meningkatnya jumlah penduduk tiap tahun menyebabkan kebutuhan fasilitas umum dan sosial di Kabupaten Serang pun semakin meningkat. Fasilitas umum dan sosial yang dimaksud seperti pendidikan, peribadatan, kesehatan, ekonomi/niaga, terminal, serta rekreasi dan olahraga.

Pada tahun 2010/2011 fasilitas pendidikan yang tersedia diantaranya adalah 1.TK (28 unit Negeri dan 1678 unit Swasta), 2. SD (4091 unit Negeri dan 424 unit Swasta), 3. SMP (534 unit Negeri dan 650 unit Swasta), 4. SMA (134 unit Negeri dan 307 unit Swasta), 5. SMA (134 unit Negeri dan 307 unit Swasta), 6. Akademik (1 unit Negeri dan 66 unit Swasta). Pada tahun 2010 fasilitas peribadatan yang tersedia diantaranya adalah 1. Masjid (25478 unit), 2. Gereja (781 unit Protestan dan 21 unit Katolik), 3. Pura (12 unit), 4. Vihara (82 unit). Pada tahun 2010 fasilitas kesehatan yang tersedia diantaranya adalah 1. Rumah sakit (69 unit), 2. Puskesmas (208 unit). Pada tahun 2010 fasilitas ekonomi yang tersedia salah satunya Bank (289 unit). Pada tahun 2010 fasilitas Terminal yang tersedia (7 unit). Pada tahun 2010 fasilitas rekreasi dan olahraga yang tersedia 134 (unit) [2]. 


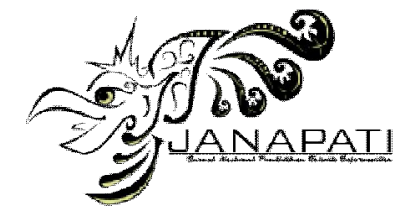

Jurnal Nasional Pendidikan Teknik Informatika (JANAPATI)

Volume 1, Nomor 3, Desember 2012

Dari data statistik tersebut maka perlu adanya sistem yang memudahkan informasi fasilitas umum dan sosial se-Kabupaten Serang. Dengan adanya pemetaan lokasi mengenai fasilitas umum dan sosial, maka informasi yang didapat akan lebih akurat dan up-to-date. Selain itu, melalui pemetaan pengambilan keputusan untuk mendirikan fasilitas umum dan sosial baru dapat dilakukan dengan mudah dan cepat.

Untuk mempermudah penyajian informasi mengenai perkembangan fasilitas umum dan sosial maka dibutuhkan suatu teknologi informasi yang lebih mudah dipahami yaitu melalui Sistem Informasi Geografis (SIG). SIG merupakan suatu sistem informasi yang dirancang untuk bekerja dengan data yang bereferensi spasial atau berkoordinat geografi. Disamping itu, GIS juga dapat menggabungkan data, mengatur data dan melakukan analisis data yang akhirnya akan menghasilkan keluaran yang dapat dijadikan acuan dalam pengambilan keputusan pada masalah yang berhubungan dengan geografi [3].

Pendekatan keruangan atau spasial sangat penting di dalam melakukan analisis fenomena yang terjadi di bumi ini, baik itu yang sifatnya fisik maupun bersifat sosial kemasyarakatan seperti ekonomi, lingkungan, budaya, dan sebagainya. Oleh karena itu, jika fenomena itu bisa ditangkap informasinya secara utuh berikut lokasi dan polanya, hal tersebut bisa membantu dalam menyelesaikan atau mencari solusi dari permasalahan terkait. Salah satu contoh kasusnya adalah pemetaan populasi penduduk dan komodo di taman nasional komodo [4], dengan menggunakan SIG kita dapat mengetahui pola dan fenomena yang terjadi mengenai hewan satwa komodo dan kependudukan di taman nasional komodo. Contoh kasus yang lain adalah mengenai sistem informasi geografis industri di Kabupaten Kudus [5], dengan SIG, informasi mengenai perkembangan industri di wilayah tertentu dapat ditangkap dan diolah sesuai dengan kebutuhan penggunanya.

\subsection{Metodologi Penelitian}

Untuk menyelesaikan masalah diatas, maka digunakan metode sebagai berikut:

1) Kajian pustaka tentang SIG dan Mapserver.

2) Melakukan survei dan analisis sistem informasi geografis ke Dinas Tata Ruang Bangunan dan Perumahan Kabupaten Serang.

3) Membuat rancangan sistem informasi geografis.

4) Melakukan implementasi perangkat lunak sesuai dengan hasil studi pustaka dan analisis.

5) Menguji perangkat lunak yang telah dibangun.

\section{Landasan Teori}

\subsection{Tinjauan Pustaka}

\subsubsection{Sistem Informasi Geografis}

SIG merupakan suatu sistem yang terdiri dari perangkat keras, perangkat lunak, data, manusia, organisasi dan lembaga yang digunakan untuk mengumpulkan, menyimpan, menganalisa dan menyebarkan informasi-informasi mengenai daerah-daerah di permukaan bumi [6]. Dengan metodologi SIG dapat memberikan kontribusi dengan cara memanipulasi data dan melakukan analisis yang diperlukan dengan waktu yang singkat dan murah, dan SIG juga berkontribusi untuk menghasilkan bentuk yang berbeda yang dapat disajikan secara grafis [7].

\subsubsection{Subsistem pada Sistem Informasi Geografis [8]}

Sistem informasi geografis dapat diuraikan menjadi beberapa subsistem:

1) Data Input. Subsistem ini bertugas untuk mengumpulkan dan mempersiapkan data spasial dan atribut dari berbagai sumber. Subsistem ini bertanggung jawab dalam mengkonversi atau mentransformasikan format-format data aslinya ke dalam format yang dapat digunakan SIG. 


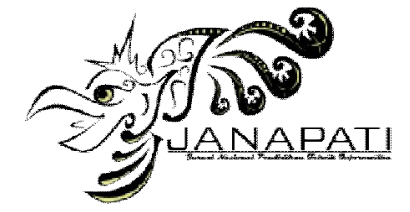

Jurnal Nasional Pendidikan Teknik Informatika (JANAPATI)

Volume 1, Nomor 3, Desember 2012

2) Data Output. Subsistem ini menampilkan atau menghasilkan keluaran seluruh atau sebagian basis data baik dalam bentuk softcopy maupun hardcopy seperti table, grafik, peta dan lain-lain.

3) Data Management. Subsistem ini mengorganisasikan baik data spasial maupun atribut ke dalam sebuah basisdata sedemikian rupa sehingga dipanggil, di-update dan di-edit.

4) Data Manipulasi dan Analisis. Subsistem ini menentukan informasi-informasi yang dapat dihasilkan oleh SIG. Selain itu, subsistem ini juga melakukan manipulasi dan pemodelan data untuk menghasilkan informasi yang diharapkan.

\subsubsection{Model Data [9]}

Terdapat dua model data atau gambar yang digunakan dalam SIG, yakni:

1) Raster. Disebut juga bitmap, adalah gambar yang komposisinya terdiri atas titiktitik berbentuk bujur sangkar, yang dinamakan dengan pixel, yang disusun pada suatu grid. Memodifikasi raster berarti memodifikasi tiap pixel. Raster bersifat bergantung pada resolusi, artinya menampilkan gambar yang terpaku pada resolusi tertentu. Jadi, ketika gambar tersebut diperkecil atau diperbesar, kualitas gambar akan berubah. Contoh image foto dan gambar.

2) Vektor. Melakukan proses pengolahan data atau gambar menggunakan garis dan kurva, yang memuat informasi dan warna, dimensi serta posisi. Vektor bersifat tidak bergantung pada resolusi, artinya vektor dapat berubah-ubah baik bentuk, ukuran, posisi atau warnanya pada resolusi berapapun tanpa mengubah kualitas tampilannya. Vektor dapat pula berupa sebuah titik tunggal. Contoh jalan, sungai, titik dan area.

\subsubsection{Mapserver}

Mapserver merupakan aplikasi freeware dan opensource yang digunakan untuk mengembangkan aplikasi-aplikasi internet-based yang melibatkan spasial. Mapserver memiliki cukup fungsionalitas inti SIG yang dapat mendukung berbagai aplikasi web terkait spasial. Selain itu, mapserver juga sangat unggul di dalam mengubah data spasial (citra, data, vektor, dan peta dijital) untuk aplikasi web.

Untuk menjalankan dan menampilkan peta yang dihasilkan oleh mapserver, diperlukan dua file yaitu mapfile dan html file. Mapfile berisikan konfigurasi penyajian peta yang ditulis dalam bahasa dan sintaks tersendiri. Informasi ini kemudian diolah dan disajikan oleh program mapserver. Sedangkan file HTML digunakan untuk melakukan format penyajian hasil peta. File HTML bisa berupa HTML biasa atau template yag disisipkan sintaks mapserver atau file HTML yang disisipkan PHP Mapscript [10].

\subsubsection{MySQL Spasial}

MySQL spasial menyediakan objek dan operasi SIG agar dapat diekstensi ke database berbasis SQL relasional. Ada empat hal penting yang perlu diketahui:

- Tipe Data. Perlu ada tipe data untuk menyimpan informasi SIG. Contohnya adalah dengan Point dalam sistem 2-dimensi.

- Operasi. Perlu ada untuk menjadi operator tambahan dalam mendukung pengelolaan multidimensi objek. Contoh sebuah fungsi yang menghitung luas berbentuk Area Poligon.

- Kemampuan untuk input dan output data. Untuk membuat sistem interoperable Open Geospatial Consortium (OGC) telah ditetapkan isi dari objek SIG diwakili dalam format biner dan teks.

- Pengindeksan data spasial. Untuk menggunakan beberapa operator berbeda diperlukan alat pengindeksan data SIG [11].

MySQL merupakan RDBMS (Relational Database Management System) yang mulai versi 4.1 menambahkan ekstensi spasial pada sistem basis datanya [12]. Ekstensi 


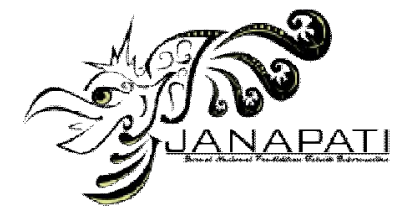

ISSN 2089-8673

Jurnal Nasional Pendidikan Teknik Informatika (JANAPATI)

Volume 1, Nomor 3, Desember 2012

spasial memungkinkan untuk menyimpan objek-objek geografis yang dapat dipakai dalam aplikasi SIG. Kaitannya dengan hal ini, berdasarkan spesifikasi dari OGC, setiap objek MySQL spasial (layer) disimpan pada tabel yang terpisah dalam database, dengan satu record pada tabel dari setiap elemen spasial (spatial feature). Di dalam tabel spatial, kolom geometry menyimpan informasi geometris pada masing-masing record. Kolom geometry mendukung untuk menyimpan point, line, polygon, multipoint, multiline, dan multipolygon[13].

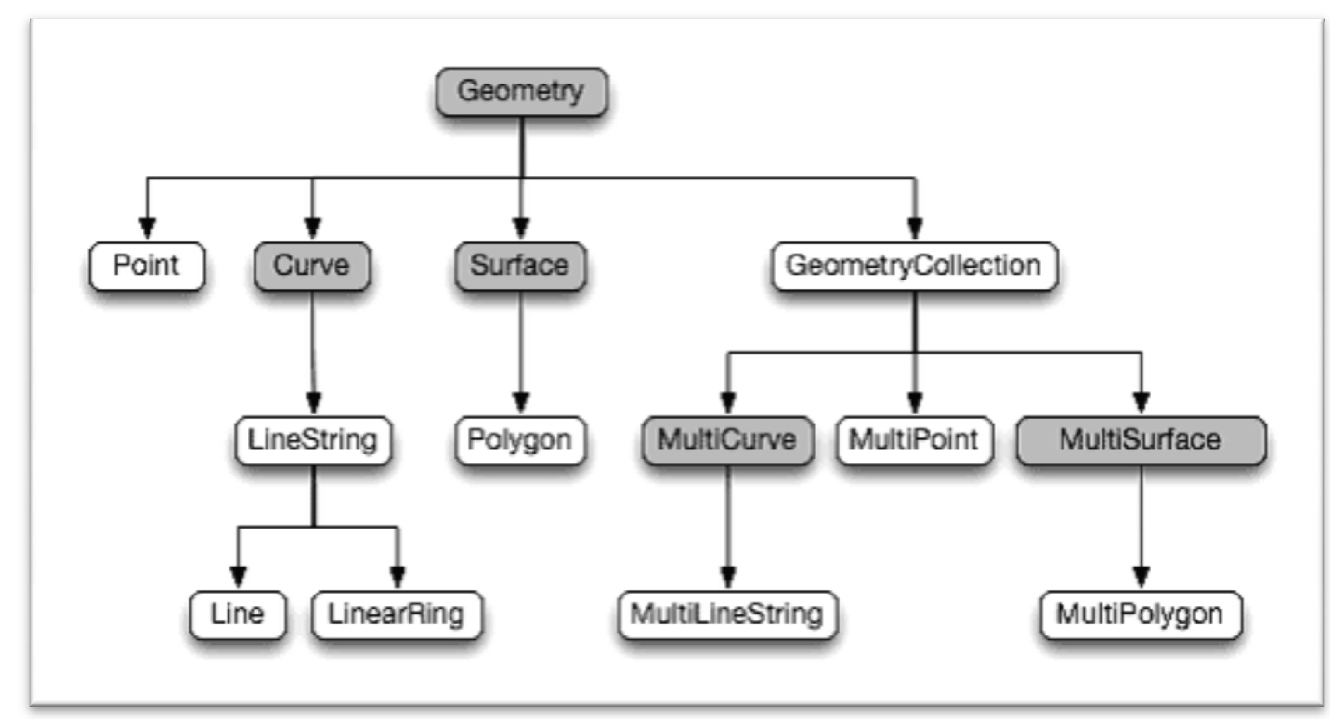

Gambar 1 Hirarki Tipe Data Mysql Spasial

Tipe data geometry secara hirarkis dapat dibagi lagi menjadi beberapa tipe data yang lebih spesifik (Gambar 1). Pada gambar 1 dapat dilihat geometri bertipe abstrak (berwarna abuabu) yang berarti tipe data tersebut hanya dapat diisi dengan tipe data spasial yang lain, termasuk geometry. Dari beberapa tipe data abstrak tersebut hanya geometry yang dapat digunakan sebagai tipe kolom [14].

\section{Analisis dan Usulan Model}

\subsection{Analisis Kondisi Eksisting}

Setelah dilakukan survei maka dapat diketahui bahwa Dinas Tata Ruang Bangunan dan Perumahan (DTRB) Kabupaten Serang adalah dinas yang bergerak dibidang perencanaan, tata ruang, tata bangunan, tata kota dan perumahan. Yang bertanggung jawab dalam merencanakan penyusunan program dan pengawasan khususnya mengenai fasilitas umum dan fasilitas sosial adalah DTRB bidang tata kota.

Untuk proses pembangunan fasilitas baru dibutuhkan ketentuan dan aturan-aturan tertentu sesuai dengan perencanaan dan penyusunan yang dibuat DTRB. Untuk saat ini DTRB bidang tata kota hanya menerima data-data yang ada pada bidang tata kota itu sendiri maupun data hasil survei pendataan. Data-data tersebut kemudian diolah menjadi arsip berupa file .xls, .xml dan tampilan peta berupa hardcopy, mengenai fasilitas di Kabupaten Serang. Tujuan adanya arsip-arsp tersebut adalah untuk keperluan DTRB dalam memberikan informasi fasilitas di wilayah Kabupaten Serang kepada pejabat yang berwenang dalam rangka pengawasan, evaluasi tata kota, perencanaan dan pengambilan keputusan. Karena entry data yang ada pada dinas tersebut belum dimasukkan ke dalam suatu sistem informasi atau masih dilakukan secara manual. Maka dari itu peneliti mencoba mengusulkan untuk membuat suatu sistem untuk melakukan pengawasan atas rencana penyusunan yang dapat 


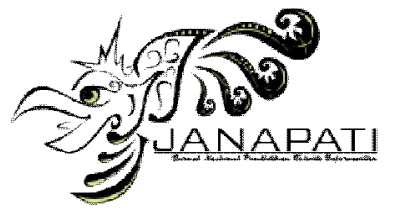

ISSN 2089-8673

Jurnal Nasional Pendidikan Teknik Informatika (JANAPATI)

Volume 1, Nomor 3, Desember 2012

mengkoordinir, mengelola dan dapat melakukan penataan tata kota agar lebih terstruktur dan terorganisasi baik untuk jangka pendek maupun jangka panjang.

Faktor-faktor penentu fasilitas tersebut dapat dibangun salah satunya adalah karena belum adanya fasilitas yang tersedia pada wilayah tersebut. Namun selain itu masih ada faktor-faktor lain yang menjadi penentu agar fasilitas dapat dibangun, tergantung dari kebutuhan dan pola suatu wilayah dan hal tersebut juga harus sesuai dengan perencanaan penyusunan program yang telah ditetapkan oleh DTRB.

\subsection{Analisis dan Usulan Penerapan SIG}

\subsubsection{Informasi yang ditampilkan}

Dari hasil survei dan wawancara diketahui bahwa informasi yang perlu ditampilkan adalah:

1) Informasi fasilitas

2) Jarak antar fasilitas

3) Radius antar fasilitas

4) Informasi jumlah fasilitas yang tersedia

\subsubsection{Pengguna}

Perangkat lunak SIG ini diusulkan untuk dikelola oleh pihak terkait seperti pejabat yangberwenang di dinas tersebut (admin, super admin dan personil lapangan) terutama bidang tata kota atau pihak independen yang berkompeten untuk mengolah aplikasi ini. Untuk memelihara sistem ini dibutuhkan administrator,super administrator dan personil lapangan.Administrator (admin) bertugas untuk memasukan data dan melakukan proses verifikasiterhadap pengajuan fasilitas baru.Syarat administrator adalah mempunyai pengetahuanmengenai data spasial dan web. Sedangkan super administrator (super admin) memilikitugas untuk memelihara, melakukan konfigurasi dan menjaga perangkat lunak pada server.Syarat super administrator adalah mempunyai pengetahuan seperti cara mengelola data,basisdata, web dan konfigurasi data spasial. Personil lapangan tidak bertugas dalam mengelola dan mengolah teknologi SIG. Jadi personil lapangan bertugas untukmelakukan survei ketempat fasilitas yang diajukan untuk mengecek posisi koordinat, sekaligusjuga menghitung jarak, radius, perilaku atau keterangan fasilitas tersebut dibangun agardisesuaikan dengan yang diajukan. Selain itu personil lapangan juga harus memperbaharuidata bila menemukan data fasilitas yang belum tercatat. Syarat dari personil lapangan adalah mempunyai pengetahuan mengenai pemetaan khususnya planologi.

Selain pengguna dari pihak dinas yang terkait, SIG ini juga dapat digunakan oleh pengguna umum (masyarakat). Pengguna umum hanya dapat mengetahuiinformasi dan keberadaan atau lokasi mengenai fasilitas. Untuk mengakses situs ini, penggunaumum diharuskan untuk menggunakan komputer yang terhubung dengan internet dan monitoryang dapat menampilkan resolusi gambar yang baik. Pengguna juga diharapkan mempunyaipengetahuan mengenai cara membaca peta.

Gambar 2 berikut adalah usecase diagram yang terdapat pada sistem. Usecase diagram ini menggambarkan aksi yang dapat dilakukan oleh pengguna. 
ISSN 2089-8673

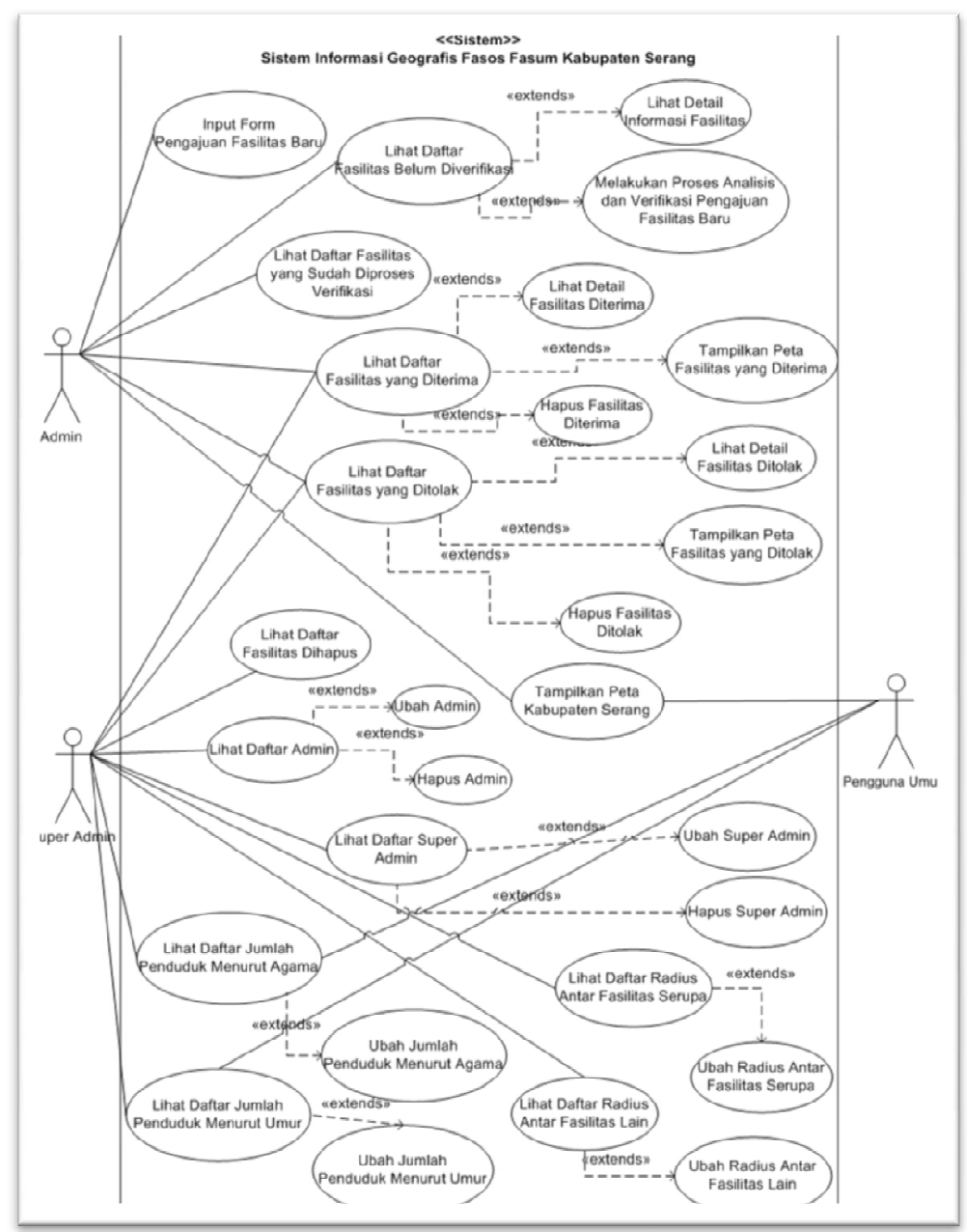

Gambar 2 Usecase diagram

\subsubsection{Data Spasial (Peta)}

Sistem ini menggunakan beberapa peta dasar atau layer yang disimpan dalam basisdata sebagai dasar untuk melaksanakan prosedur pengelolaan fasilitas. Peta-peta tersebut didapat dari hasil survei ke DTRB, dan format peta tersebut berupa fileshape ( ${ }^{*}$.shp). Data peta tersebut dibuat kedalam layer-layer agar mudah dalam menampilkan peta. Informasi dasar fasilitas dibagi menjadi beberapa layer. Layer-layer akan menyimpan detail informasi mengenai fasilitas. Berikut adalah pembagian layer tersebut:
1) Peta dasar Kabupaten Serang 1 layer
2) Peta fasilitas umum dan fasilitas sosial masing-masing 1 layer
3) Peta radius 1 layer
4) Peta symbol 1 layer
5) Peta jalan 1 layer
6) Peta raster 1 layer
7) Peta batas wilayah 1 layer
8) Peta hutan lindung dan budidaya masing-masing 1 layer

\subsubsection{Data non-spasial}




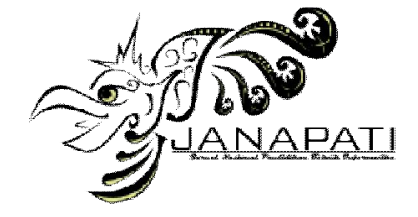

Jurnal Nasional Pendidikan Teknik Informatika (JANAPATI)
Volume 1, Nomor 3, Desember 2012

Selain data spasial yang telah disebutkan diatas, terdapat juga data non-spasial yang digunakan untuk menampilkan informasi yang melekat pada data spasial tersebut. Data-data ini nanti akan berguna untuk mengetahui hasil dari query sehingga pengguna khususnya dinas yang terkait dapat melakukan tindakan dengan cepat dan tepat terhadap pola yang terdapat pada sistem tersebut.

\subsubsection{Penerapan Sistem}

Pada saat admin memasukan data mengenai pengajuan permohonan pembangunan fasilitas baru, maka sistem akan menampilkan koordinat area fasilitas dan koordinat lokasi rencana fasilitas yang akan dibangun. Koordinat tersebut diperoleh menggunakan GPS. Secara prosedural, pengukuran fasilitas yang akan dibangun dilakukan oleh petugas DTRB yang bertindak sebagai surveyor(personil lapangan) dalam hirarki pengelola sistem.Data dan prasayarat yang belum dimasukkan kedalam sistem ini (hasil survei ke lokasi) harus sudah diisi dengan lengkap dan validsehingga ketika admin akan memasukan data kedalam sistem tidak ada kesalahan dalam input data.

Pada SIG, data yang paling penting adalah mengetahui koordinat mengenai fasilitas tersebut. Koordinat ini akan digunakan oleh sistem untuk melakukan query secara spasial mengacu pada mysql spasial untuk memperoleh informasi mengenai kondisi lingkungan dimana fasilitas akan dibangun. Kondisi fisik ini mereferensi pada data dasar, yakni informasi fasilitas, radius, dan area tertentu yang tidak dizinkan untuk dibangun fasilitas. Berdasarkan pada informasi tersebut apabila menurut data fasilitas, lokasi tersebut layak dan perlu didirikan, maka pengguna khususnya pihak terkait akan melakukan konfirmasi dan memberikan izin untuk pengajuan fasilitas baru tersebut. Apabila berdasarkan data fasilitas, lokasi tersebut tidak memungkinkan untuk pembangunan fasilitas (misalnya: merupakan wilayah yang dilindungi atau budidaya, atau berdekatan dengan fasilitas serupa) maka pengguna dapat membatalkan. Sekali lagi, data yang dimasukan kedalam sistem sebelumnya harus sudah dilakukan pengecekan dengan benar, agar data yang didapat sesuai dengan kondisi lapangan dan verifikasi data dapat dilakukan dengan benar.

\subsubsection{Rancangan Antar muka}

Untuk rancangan antar muka yang menampilkan peta dibuat fitur navigasi dan legenda untukkemudahan pengguna dalam menggunakan peta. Gambar 3 menjelaskan fitur atau menu yang tersedia pada sistem ini. 
ISSN 2089-8673

Jurnal Nasional Pendidikan Teknik Informatika (JANAPATI)

Volume 1, Nomor 3, Desember 2012
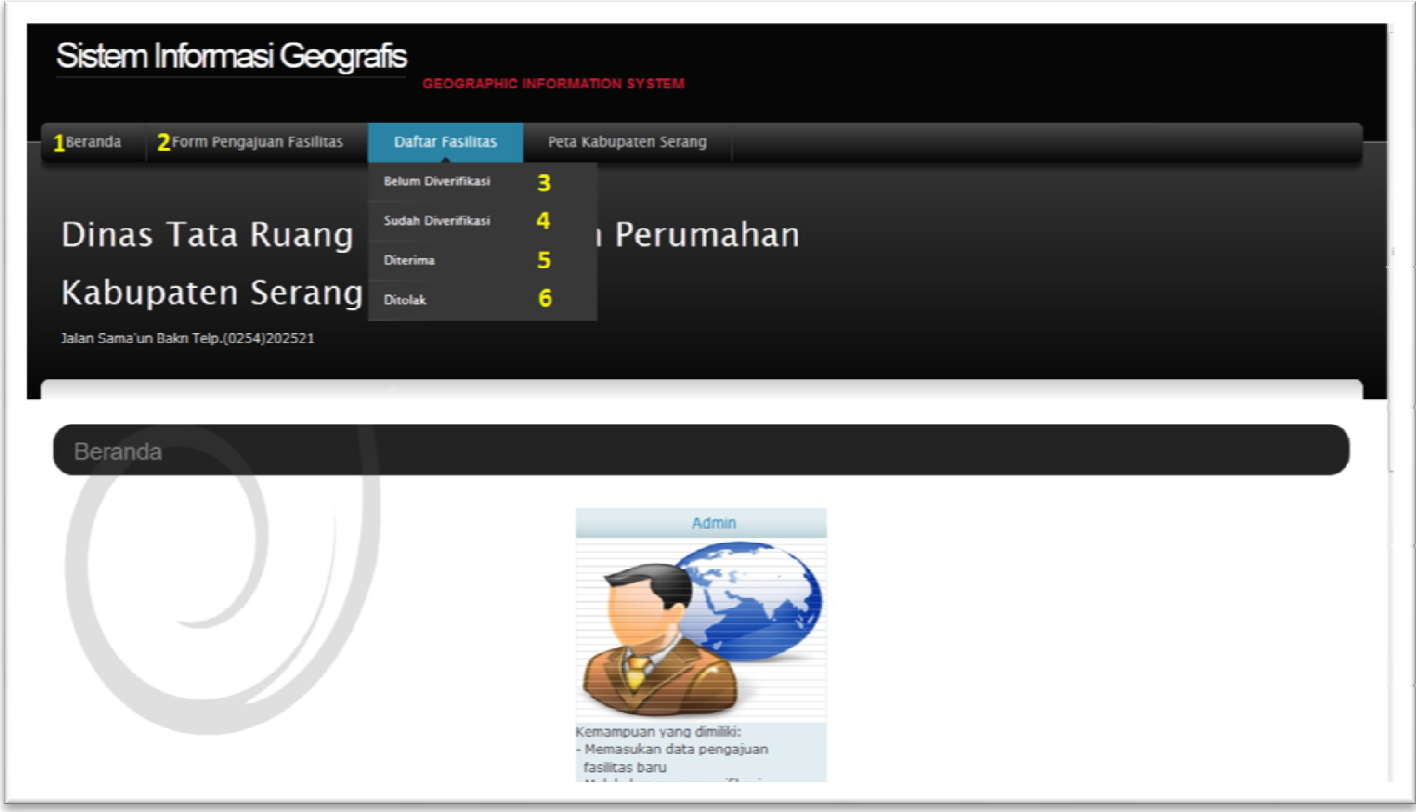

Gambar 3Menu pada sistem

Menu satu (1) merupakan menu untuk menuju halaman beranda, menu dua (2) merupakan halaman input pengajuan fasilitas baru, menu tiga (3) adalah halaman yang menyimpan daftar tabel yang akan diproses/di-verifikasi, menu empat (4) halaman yang menyimpan daftar tabel yang sudah diproses/di-verifikasi, menu lima (5) halaman yang menyimpan daftar tabel fasilitas yang diterima (diizinkan untuk mendirikan bangunan) yang didalamnya terdapat link menuju halaman peta untuk mengetahui informasi/pola alasan diterimanya. Untuk menu enam (6) sama seperti menu (5) yang menyimpan daftar tabel fasilitas yang ditolak (melanggar aturan). Dan yang terakhir adalah menu peta kabupaten serang yang merupakan menu untuk menuju peta yang menampilkan keseluruhan kabupaten serang seperti pada gambar 4 yang didalamnya terdapat navigasi, legenda, dan petanya yang menampilkan semua fasilitas yang diterima. 
ISSN 2089-8673

Jurnal Nasional Pendidikan Teknik Informatika (JANAPATI)

Volume 1, Nomor 3, Desember 2012

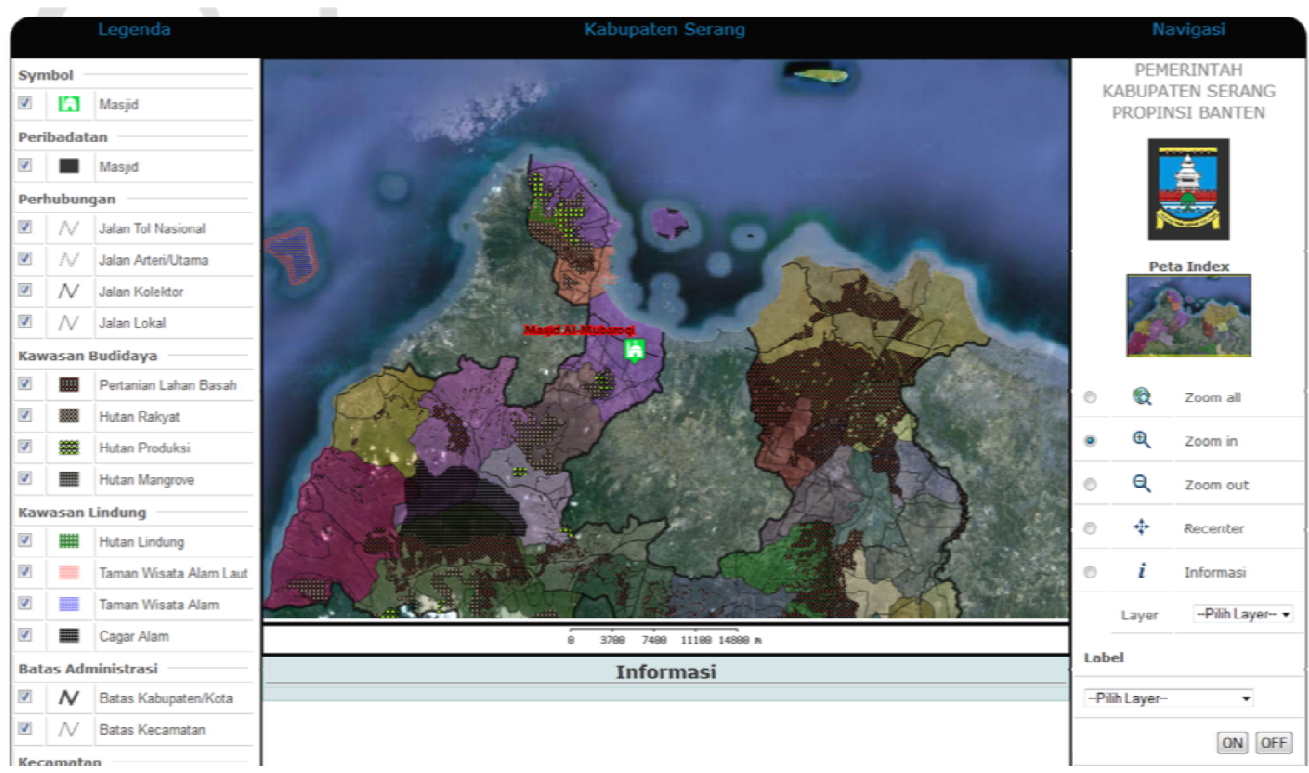

Gambar 4Halaman Peta Kabupaten Serang

\subsubsection{Rancangan Basis Data}

Dari hasil analisis dan usulan di atas maka dirancanglah basisdata untuk menyimpan data-data pada MySQL seperti pada gambar 5. Tabel pengajuan fasilitas berisi data non spasial yang memberikan informasi mengenai data fasilitas. Tabel fasilitas spasial merupakan tabel yang berisi data spasial, dimana koordinat fasilitas tersebut disimpan kedalam format mysql spasial. Tabel fasilitas sudah proses merupakan tabel untuk mengetahui fasilitas yang sudah diverifikasi/diproses baik diizinkan maupun ditolak. Sedangkan tabel yang lain merupakan turunan dari tabel pengajuan fasilitas, untuk informasi bahwa fasilitas tersebut berada diwilayah yang tidak diizinkan untuk mendirikan fasilitas atau sebaliknya dan radius tertentu baik radius yang serupa maupun radius antar fasilitas lain.

\section{Hasil Implementasi dan Pengujian}

Rancangan di atas dimplementasikan pada basis data MySQL Spasial dengan pemrograman PHP menggunakan PHP MapScript. PHP MapScript merupakan salah satu library PHP untuk mengakses MapServer. 


\section{ISSN 2089-8673}

Jurnal Nasional Pendidikan Teknik Informatika (JANAPATI)

Volume 1, Nomor 3, Desember 2012

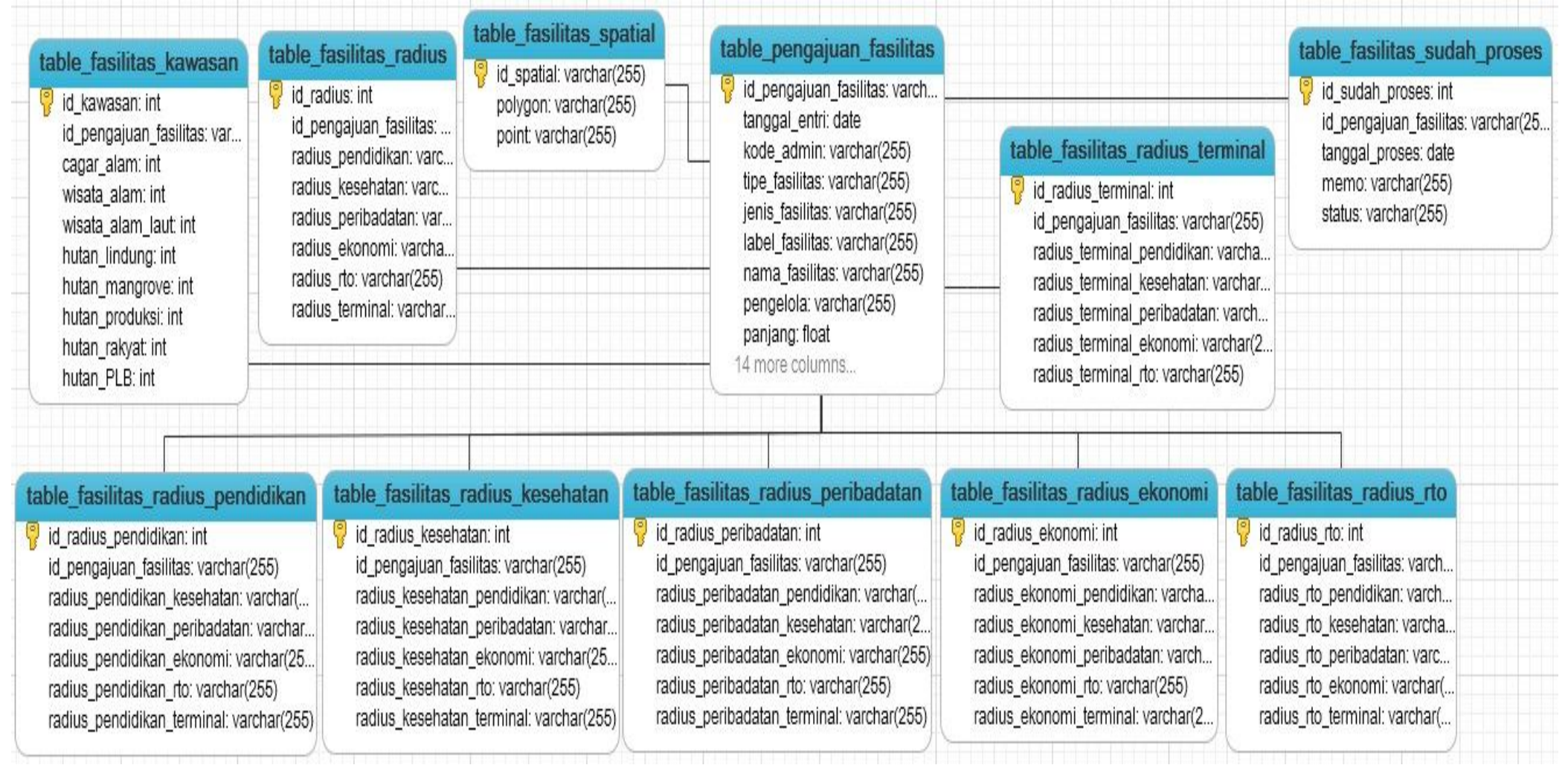

Gambar 5 Desain Database 
ISSN 2089-8673

Jurnal Nasional Pendidikan Teknik Informatika (JANAPATI) Volume 1, Nomor 3, Desember 2012 
ISSN 2089-8673

Jurnal Nasional Pendidikan Teknik Informatika (JANAPATI)

Volume 1, Nomor 3, Desember 2012

Pengujian dilakukan dengan metode black box. Selain itu, pengujian juga dilakukan dengan studi kasus. Berikut adalah contoh pengujian pada suatu kasus, dimulai dari pemasukan data sampai dengan hasil analisis SIG.

Untuk input data pengajuan fasilitas, diakses halaman pengajuan fasilitas sosial dan fasilitas umum (gambar 5). Pada halaman ini perluinput data, seperti nama fasilitas, koordinat, tipe fasilitas (umum/sosial), jenis fasilitas (pendidikan, kesehatan, peribadatan, ekonomi, terminal, rekreasi dan olahraga), pengelola fasilitas, luas, panjang dan lebar fasilitas, lokasi fasilitas, serta gambar dari fasilitas tersebut.

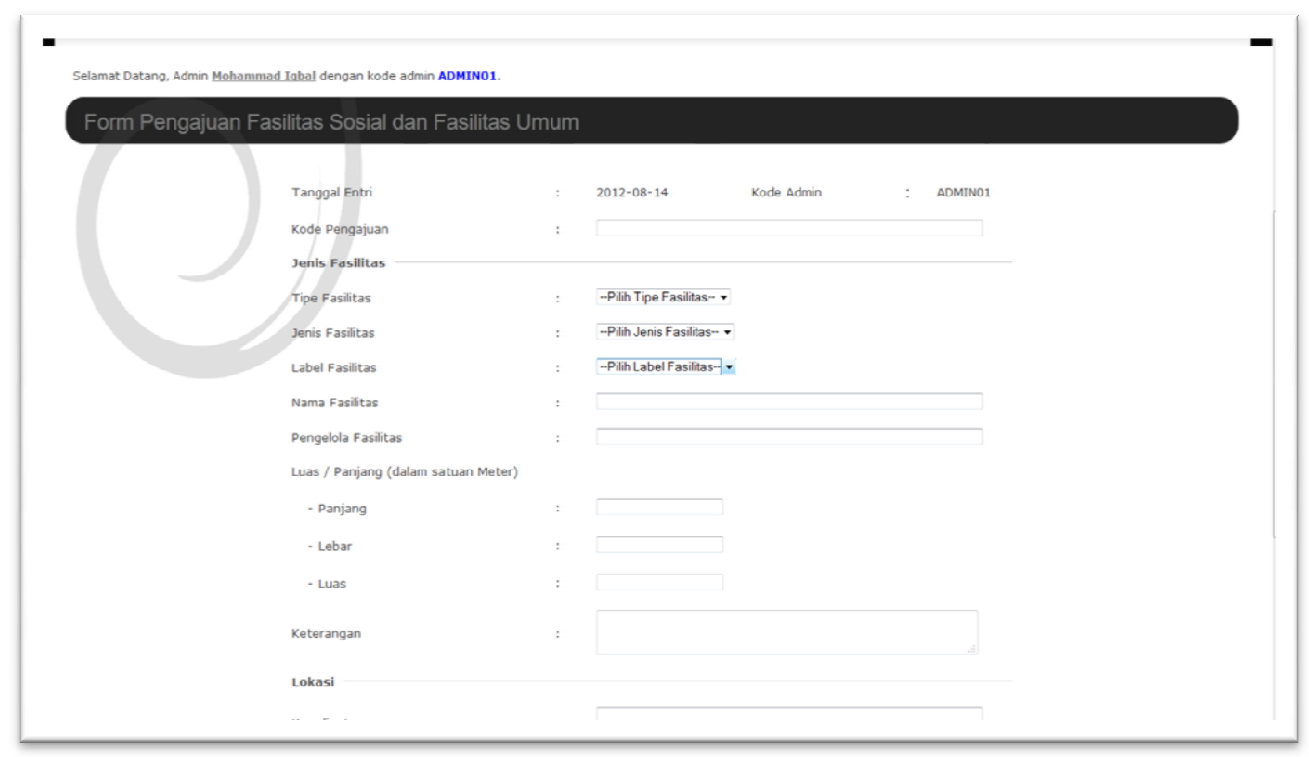

Gambar 5 Halaman Pengajuan Fasilitas Sosial dan Fasilitas Umum

Setelah melakukan input data pada halaman pengajuan fasilitas sosial dan umum, ketika mengklik submit maka akan menuju ke halaman proses verifikasi (diizinkan/ditolak) (gambar 6), halaman ini digunakan untuk mengetahui daftar fasilitas apa saja yang belum di-verifikasi. 
ISSN 2089-8673

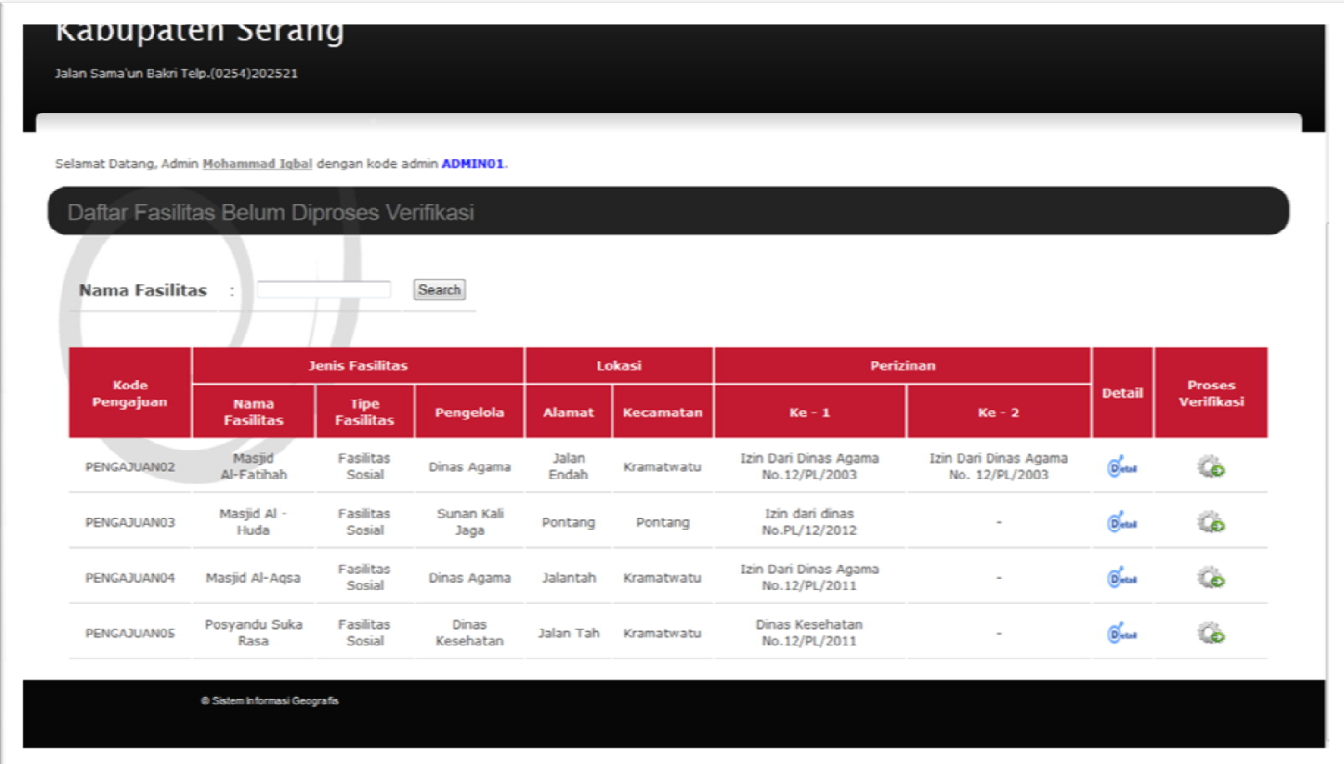

Gambar 6 Halaman Fasilitas BelumDiverifikasi

Untuk melakukan proses verifikasi, pengguna harus mengklik link proses yang nantinya akan menuju kehalaman peta (gambar 7), dimana terdapat informasi mengenai kelayakan apakah fasilitas tersebut memenuhi syarat dan aturan sebagaimana yang telah ditetapkan oleh perencanaan penyusunan program DTRB. Contoh pengujian berikut adalah ketika posisi fasilitas berada pada kawasan budidaya seperti pertanian lahan basah.

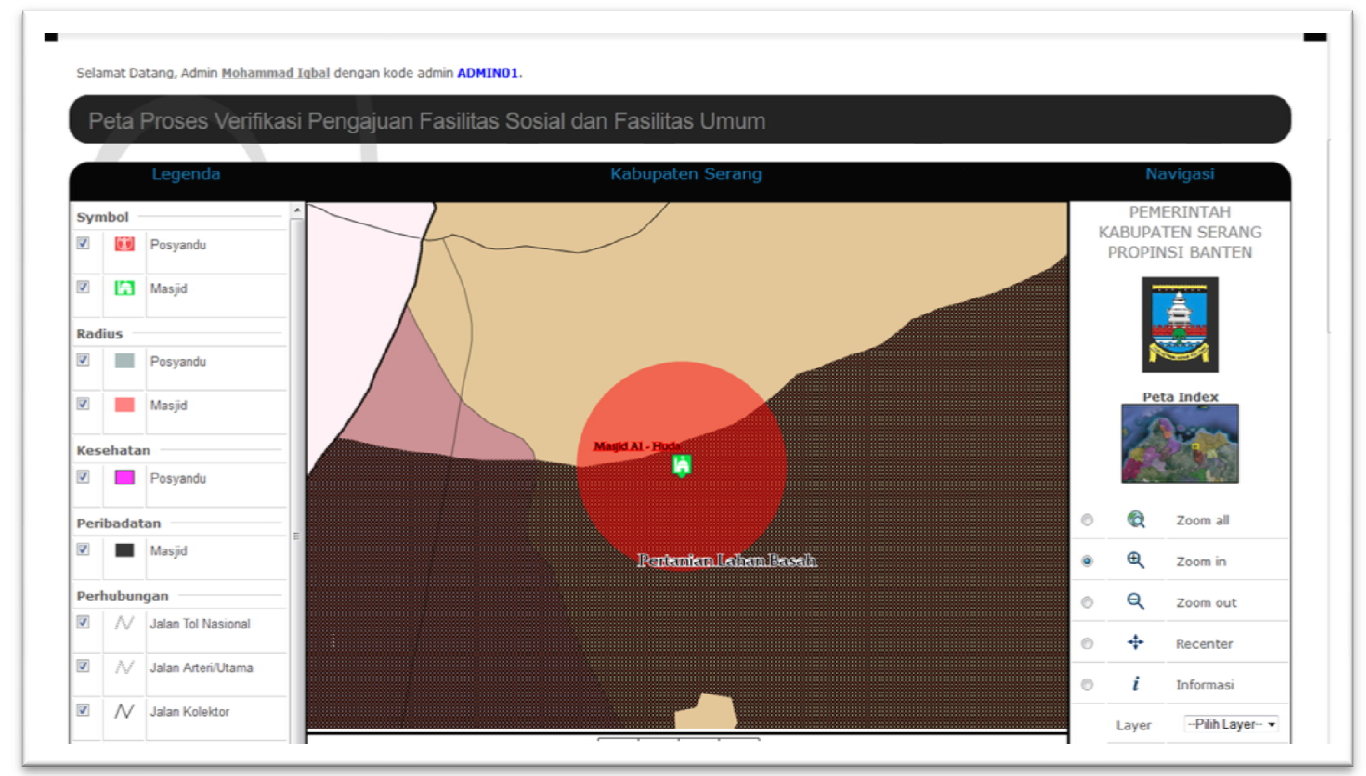

Gambar 7 Halaman Peta yang akan di proses (1) 
ISSN 2089-8673

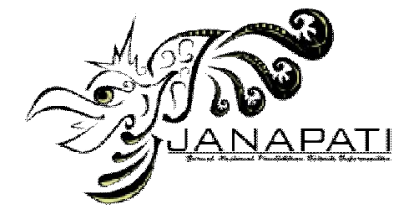

Jurnal Nasional Pendidikan Teknik Informatika (JANAPATI)

Volume 1, Nomor 3, Desember 2012

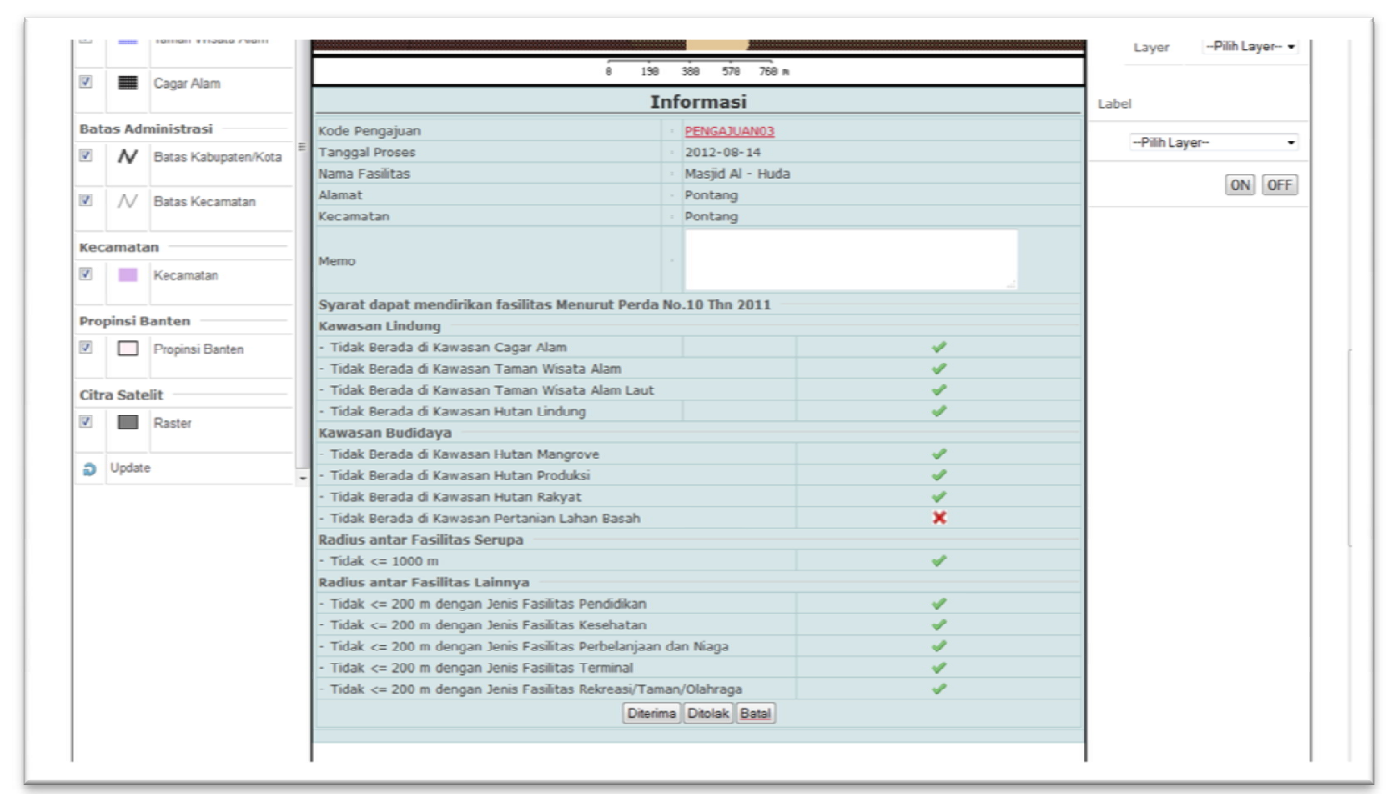

Gambar 8 Halaman Peta yang akan di proses (2)

Pada gambar 7 terlihat bahwa fasilitas tersebut berada di wilayah Pertanian lahan basah, dan menurut aturan DTRB, jika berada diwilayah tersebut maka fasilitas tersebut tidak diperbolehkan untuk didirikan sehingga akan menampilkan informasi seperti pada gambar 8 .

Seperti yang terlihat pada gambar 8 karena pada gambar 7 fasilitas berada pada kawasan pertanian lahan basah, sehingga muncul tanda silang $(X)$ seperti yang ditujukkan pada gambar 8. Untuk kasus yang terjadi seperti gambar diatas, maka admin tidak akan memberikan izin untuk mendirikan bangunan fasilitas pada wilayah tersebut. Namun jika fasilitas tersebuttetap ingin didirikanharus berdasarkan perizinan dari semua pihak, selama memiliki alasan yang tepat dan jelas kenapa perlu didirikan. Sehingga admin dapat memberikan izin tetapi harus menuliskan alasan tersebut pada bagian memo, sehingga alasan dapat mendirikan bangunan di wilayah tersebut dapat dipertanggungjawabkan.

Setelah proses verifikasi selesai dilakukan maka fasilitas tersebut akan berada pada daftar fasilitas yang sudah diverifikasi (baik ditolak maupun diterima) dan daftar fasilitasyang diterima jika fasilitas tersebut diterima (begitu juga sebaliknya jika ditolak). Berikut gambar 9 yang merupakan daftar fasilitas yang diterima. 


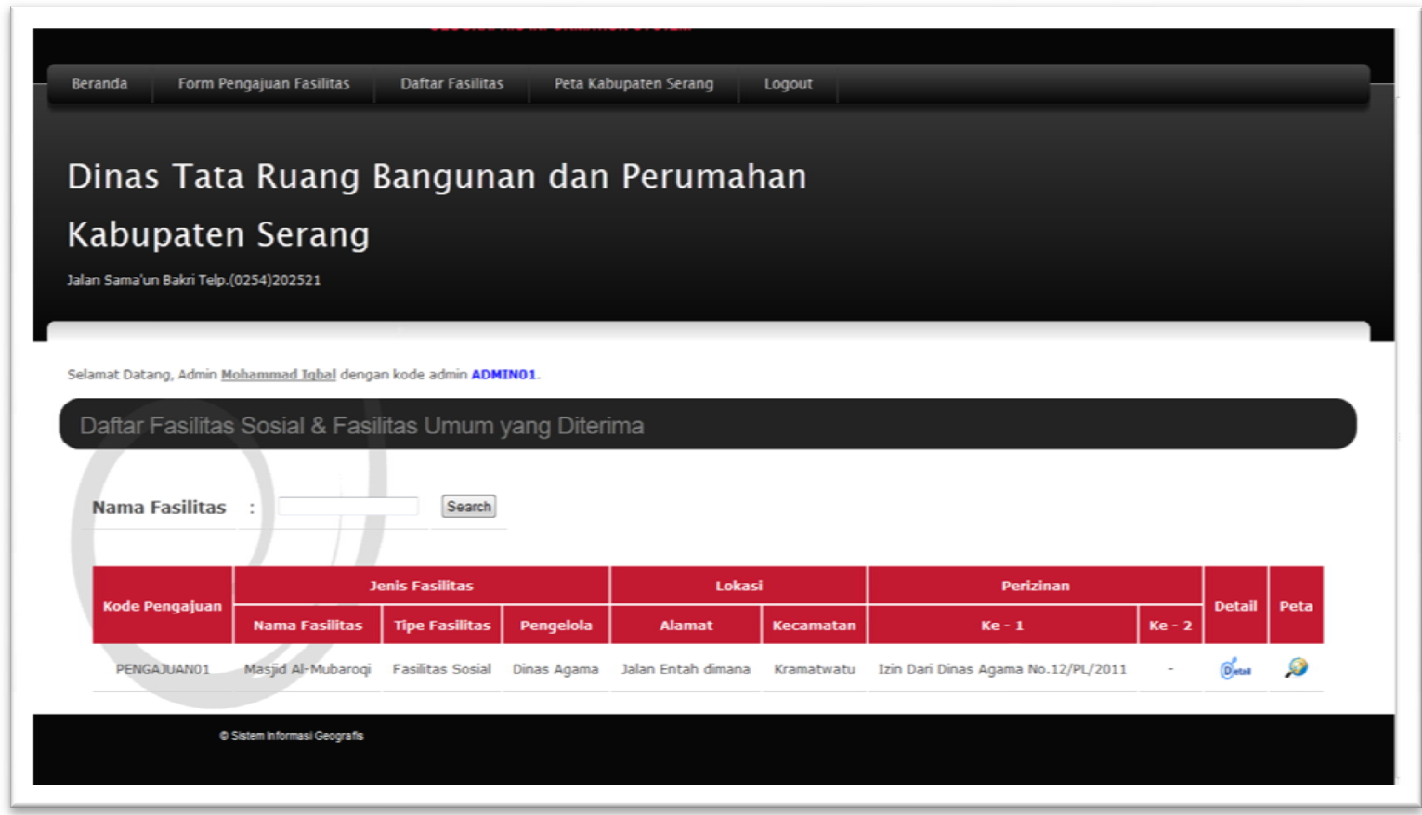

Gambar 9 Daftar Fasilitas yang Diterima

Pada daftar fasilitas tersebut terdapat action"peta" yang digunakan untuk melihat halaman peta yang bertujuan untuk mengetahui informasi dan alasan peta tersebut diterima.

Selain pengujian yang dijelaskan diatas, sistem ini juga dapat mengecek fasilitas yang berada pada jarak tertentu, salah satu contohnya jika akan mendirikan fasilitas pendidikan seperti SLTA tidak boleh berjarak dibawah 1.000meter dengan SLTA lain. Selain fasilitas yang serupa seperti pendidikan terdapat juga aturan tidak boleh berdekatan dengan fasilitas niaga/perdagangan seperti pasar minimal 200 meter, karena akan mengganggu aktivitas sekolah.

\section{Analisis Manfaat Hasil Implementasi SIG}

Dengan diimplementasikannya SIG selain memberikan manfaat efektivitas waktu dan penyajian, juga dapat memberikan manfaat dan tujuan lain seperti :

- Melakukan melaksanakan manajemen file database fasilitas sosial dan umum, sehingga didapat database yang terorganisasi dengan baik serta mudah di akses oleh aparatur dinas yang memerlukan.

- Tersedianya data dan informasi fasilitas sosial dan umum yang dapat dioptimalkan sebagai data evaluasi, perencanaan kegiatan, penyususnan program maupun kegiatan pengawasan.

- Memberikan informasi data fasilitas sosial dan umum di wilayah kabupaten serang kepada pejabat yang berwenang dalam rangka monitoring kegiatan, perencanaan dan pengambilan keputusan.

\section{Kesimpulan}

Dari hasil pengujian perangkat lunak SIG mengenai fasilitas umum dan sosialkabupaten serang, dapat disimpulkan bahwa:

1. MySQL versi 5 keatas sudah mampu dalam menyimpan dan menampilkan objek spasial.

2. Dengan teknologi MapServer, MySQL Spasial dan PHP script akan memudahkan bagi pengembang untuk membuat pemodelan spasial maupun non spasial. 
ISSN 2089-8673

Jurnal Nasional Pendidikan Teknik Informatika (JANAPATI)

Volume 1, Nomor 3, Desember 2012

3. SIG sangat bermanfaat untuk melaksanakan manajemen fasilitassosial dan fasilitas umum di Kabupaten Serang.Banyak fungsi manajerial dan pengambilan keputusan yang dapat dibantu menggunakan sistem ini, misalnya pemberian izin yang memungkinkan tersedianya informasikewilayahan secara cepat, menyangkut variable-variable penting yang digunakan dalamupaya rencana tata ruang bangunan yang baik.

\section{Daftar Pustaka}

[1]. Demers, M.N. 1997. Fundamentals of Geographic Information Systems. John Wiley \& Sons, Inc.

[2]. BPS. 2012. Badan Pusat Statistik (BPS), tersedia pada : http://banten.bps.go.id/. [29 Juni 2012].

[3]. Depdiknas. 2010. Geographic Information System (GIS), tersedia pada : http://www.sig.depdiknas.go.id/. [18 November 2010].

[4]. A., Ahmat, M., Abdul, Husain. 2012. Perancangan Sistem Informasi Geografis Pemetaan Populasi Penduduk Dan Komodo Di Taman Nasional Komodo. Prosiding SENTIA, Vol. 4, B-86 - B-91.

[5]. S., Pratomo. 2012. Sistem Informasi Geografis Industri Di Kabupaten Kudus. Seminar Nasional Teknologi Informasi \& Komunikasi Terapan (Semantik), 235 - 240.

[6]. Chrisman, Nicholas. 1997. Exploring Geographical Information System. John Wiley \& Sons, Inc.

[7]. Ali Yalcim and Fikri Bulut. 2006. Landslide susceptibility mapping using GIS and digital photogrammetric techniques; a case study form Ardesen (NE-Turkey). Springer Science+Businnes Media B.V.

[8]. Prahasta, Eddy. 2005a. Subsistem SIG. Dalam: Prahasta, Eddy. (eds.) Sistem Informasi Geografis Konsep-konsep Dasar.2005. Bandung: Informatika.

[9]. Prahasta, Eddy. 2005b. Model Data. Dalam: Prahasta, Eddy. (eds.) Sistem Informasi Geografis Konsep-konsep Dasar.2005. Bandung: Informatika.

[10]. Nuryadin, Ruslan. 2005. Tentang Mapserver. Dalam: Nuryadin, Ruslan. (eds.) Panduan Menggunakan Mapserver. 2005. Bandung: Informatika.

[11]. Karlsson, Andreas. 2011a. GIS and Spatia Extensions with MySQL. Tersedia pada http://dev.mysql.com/tech-resources/articles/4.1/gis-with-mysql.html, [26 Maret 2011].

[12]. Haryanto, S. 2005. SQL: Kumpulan Resep Query Menggunakan MySQL. Jakarta: Dian Rakyat.

[13]. Jumadi \& Widiadi, S. 2009. Pengembangan Aplikasi Sistem Informasi Geografis (SIG) Berbasis Web Untuk Manajemen Pemanfaatan Air Tanah Menggunakan PHP, Java Dan Mysql Spatial. Forum Geografi, Vol. 23, No. 2, 123-138.

[14]. Karlsson, Andreas. 2011b. GIS and Spatia Extensions with MySQL. Tersedia pada http://dev.mysql.com/tech-resources/articles/4.1/gis-with-mysql.html, [26 Maret 2011]. 